\title{
The effect of electronic collective scientific conversations on developing creative thinking and the ability of discussion among technical university students
}

\author{
Ethar Abdul muhsin Qasim Al- Mayyahi ${ }^{1}$ and Mowaffaq Abdulaziz Al-Hisnawi ${ }^{2}$ \\ ${ }^{1}$ University of Kufa, Faculty of Education \# \\ ${ }^{2}$ Southern Technical University - Technical Institute in Nasiriyah \\ ethara.almayyahi@uokufa.edu.iq,Pdmh2005@stu.edu.iq
}

\begin{abstract}
This research aims to know the effect of electronic collective scientific conversations in developing the creative thinking and the ability to debate among technical university students. The research sample consisted of (46) male and female students for the academic year (2017-2018). They are divided into two groups of equal number with equivalent number of variables based on test and control. Five subjects of theoretical electrical installations were chosen during the second semester, the teaching plans were prepared, as well as the research tools, which are the test (experimental) of creative thinking and the form for noticing the ability was discussed and their psychometric properties extracted. The research outcomes the students of the test group who used electronic collective scientific conversations were superior in creative thinking and the ability to debate over the students of the control group who used the usual method. In light of this, the researchers concluded that there is a positive effect of electronic collective scientific conversations, and they recommended their use in the process of teaching students in technical universities. The effective of the electronic group scientific chatting to the growth of the creative thinking and the ability to the discuses to the technical university students
\end{abstract}

Keywords: Electronic conversations, Creative thinking,

\section{The research problem and its importance}

1.1 - the research problem:

As a result of scientific and technological developments and the emergence of the Internet, new technologies and methods for learning and social communication have emerged [1-5]. New fields of social, cultural and scientific communication have been created that were not previously familiar among individuals of various segments and institutions in various disciplines and goals, which made it possible to communicate in electronic group conversations via the Internet in which individuals participate to make groups with different goals close to the reality. The Educators have thought about 
the importance of using all the data and results of scientific and technological development and benefiting from them in enhancing the positive role of the student in the learning process, because it is the basic base on which the development and construction process in society is based in the present and the future [6-8].

The effective use of social networks and electronic conversations between students and teachers have become necessary in educational institutions, including university institutions, in order to achieve desirable positive goals that are precisely defined and planned in advance, including working to develop thinking of its various types, including creative thinking, and developing the ability to debate among university students, especially the students of technical universities [9-13]. The research aims to know the impact of electronic collective scientific conversations in developing creative thinking and the ability to debate among students of technical universities in order to reach experimental results that can be used in developing the positive and active role of the university student in the learning process and developing the teaching methods that are used [14-17].

\section{2 - the importance of the research:}

The four technical universities that emerged from the Technical Education Authority represent the body directly responsible for everything related to technical education in Iraq in terms of its philosophy, goals, programs, curricula, and present and future plans. Therefore, these universities, their teachers and students gain their great importance from the importance of technical education and its active role in the process of construction and comprehensive development in all its aspects and fields in Iraqi society. In light of this, a serious and orderly endeavor should be made, in accordance with organized and purposeful educational plans, in order to develop the educational process in these universities and build the personality of the qualitative student and grant him a positive and active role in the learning process in order to be able to keep pace with the data of scientific and technological development and interact with it positively, whether that interaction is when he is a university student or after graduation and engage in the field of practical life. The technical university students represent the middle technical cadres of the workforce pyramid in society, and they are the pillar of technical construction in it, and they are the most dealing with modern technologies available in the labor and production sector in its various disciplines in various fields of engineering, medical, administrative, agricultural and applied arts [18-19].

\section{3 - Research Objectives:}

The research aims to know the effect of electronic collective scientific conversations in developing creative thinking and the ability to debate among technical university students.

\section{4 - Research Limits:}

1- Spatial: The Technical Institute in Nasiriyah at the Southern Technical University in the Republic of Iraq

2- Temporal: the academic year (2017-2018).

3- Humanity: first-year students in the Department of Electrical Techniques.

4- Cognitive: five topics from the subject of theoretical electrical installations.

\section{5 - Research Hypotheses:}

1 - There are no statistically significant differences at the level of significance $(0.05)$ between the average scores of the experimental group students who used electronic collective scientific conversations and the average scores of the control group students who used the usual method in the creative thinking test. 
2- There are no statistically significant differences at the level of significance $(0.05)$ between the average scores of the experimental group students who used electronic collective scientific conversations and the average scores of the control group students who used the normal method in the discussion ability observation form.

\section{6 - Defining the terms:}

1 - Group Chatting: It is communication among many people and it allows them to learn with each other. For the conversation to be successful, the participants must strike a practical balance in contributions. A successful conversation includes the exchange of interesting ideas among the speakers by finding a specific topic of interest to them and they can exchange ideas about it. (Wikipedia, the free online encyclopedia [16])

Procedural definition: It is an electronic communication through the WhatsApp application via the Internet between a researcher and students of the experimental group, the research sample in the first stage in the Department of Electrical Technologies at the Technical Institute in Nasiriyah and among students themselves in order to establish electronic scientific group conversations to conduct discussions on the subject of Electrical Installations (theoretical lectures) in order to obtain additional information for the purpose of developing creative thinking and the ability to discuss.

2- (Reinforcement): it is defined by (Al-Sabaty 2004 [8]) as a planned activity that aims to bring about changes in the individual, the group, and the organization in terms of information and experiences, in terms of performance, working methods, and in terms of attitudes and behavior, which makes the individual and the group fit to occupy their jobs efficiently and with high productivity. (Al-Sabaty 2004 [8]).

Procedural definition: It is the magnitude of development and improvement in creative thinking and the ability to discuss among students the research sample in the two experimental groups that used the regular method in addition to the electronic scientific group conversations and the control group that used the normal method only after the completion of the experiment through their answers to the creative thinking test and a form of noticing the ability to discuss that is prepared by the researchers.

3 - Creative Thinking: it is defined by (Abdul-Hadi and others 2003 [11]): It is one of the advanced types of thinking where, through its practice, the individual can reach unique and distinctive solutions that no one has reached. (Abdul-Hadi and others 2003 [11]).

Procedural definition: It is the ability of the research sample students in the experimental and control groups to use creative thinking skills in an unusual way when solving problems presented to them related to the subjectj This is evident from their scores in the creative thinking test prepared by the researchers

4 - The Ability to Discuss: it is defined by (Mohammed 2006 [12]): It is a situation of verbal interaction that occurs in a planned and intentional manner based on the meeting of a number of people such as the teacher and students for the purpose of exchanging ideas and opinions under the supervision of a certain leadership in order to reach specific results that agreed upon by all participants in the discussion. (Mohammed, 2006 [12]).

Procedural definition: It is the ability of the research sample students in the experimental and control groups to discuss and dialogue in the lecture among themselves and the teacher and 
this is measured by recording grades on the items of the discussion ability note form that was prepared by the researchers.

\section{Theoretical background and previous studies}

\subsection{The theoretical background:}

\subsection{1 - Electronic Societies}

Electronic societies are a natural result of scientific and technological progress occurred in modern technologies, including the network. It is a fictional simulation of a real society that is visualized and built through the capabilities provided by three-dimensional technology and graphics to produce life situations that attract those who interact with it and enter him/her in its world. (Mona, 2013, 483 [13]) and (Al-Shahrani [10]) shows that virtual education through it, is characterized by the multiplicity of services and applications it provides to educational institutions to ensure their quality, increase the efficiency of its teaching staff and students, provide multiple and renewable sources of information, increase the effectiveness of teaching and training methods, and develop the student's scientific, social and cultural personality due to the abundance of information existing in it and transcend the limits of time and space at a low cost and quickly.

(Al-Shahrani, 2008, 14 [10]) and (Kecmanovic) states that it is possible through the Internet to provide a new cooperative environment in which students can work together and share in understanding the subject matter, exchange ideas and trends and solve problems that face them cooperatively. (Kecmanovic,2000, p.73 [17])

(Al-Musa) indicates that one of the applications of these groups is the registration of teachers and students in them to benefit from the experiences of the specialists, each according to his/her specialization. As well as setting up an arena for group social conversations and joint forums for students and teachers for the purpose of exchanging points of views and ideas on various issues and discussing methods of cooperation among them. (Al-Musa, 2001, 173)

Among the important applications on the Internet, the social media application (WhatsApp), As its use and participation in it has spread to a large extent, because it contains many possibilities for exchanging information and ideas between different human cultures. It is a multi-platform instant messaging application for smartphones, and in addition to basic messages, the users can send photos, voice, video, and media messages. (Wikipedia, the free online encyclopedia [16]).

\subsection{2- Creative thinking:}

Thinking is a continuous daily process that accompanies the human being on a permanent basis and a natural performance that is carried out by the individual continuously (Al-Surour, 1996, 66 [9]). Thus, the development of thinking has taken the forefront in the goals of education In all stages of study and in all nations and populations, regardless of their degree of development. Each of (Jamal), (Jarwan) and (Al-Khalili [1,2]) indicate that there are several capabilities of creative thinking, represented by the following:

- Fluency: It represents the individual's ability to generate a large number of alternatives or ideas when responding to a particular stimulus, in addition to the ease of generating them and his ability to produce the largest possible number of ideas in a given time.

- Flexibility: it is divided into two types: spontaneous flexibility, which represents the ability to produce appropriate responses to a particular problem, and adaptive flexibility, which represents the ability to change the way of thinking about a particular problem and responding to it. 
- Originality: It is the ability to quickly produce the largest possible number of serious indirect or unusual responses, and it expresses the uniqueness and excellence in the divergent production of the meanings transformations.

- Verbosity: It represents the ability to add new information, details, and components to the primary forms, such as expanding a certain idea or clarifying an ambiguous topic.

- Sensitivity to problems: It is the ability to perceive weaknesses in an exciting situation, as it means insufficiencies and shortcomings because his/her view of the problem is unusual.

(Jamel, 2005, 50), (Jarwan, 2002), (Jarwan, 2009), (Al-Khalili, 2005, 141) (Dalloul and Al-Assi) $[1,2,6,7]$ confirmed that there are several elements for the success of creative thinking in educational institutions, including the following:

- Finding the appropriate educational environment that helps the student to think, and this is done by paying attention to the conditions of the educational environment, Focusing on the student's attention and training.

- The focused processing for the purpose of refreshing memory and emphasizing information and processing it accurately.

- Strengthening the thought and accepting students' positive attitudes and directing them in the desired direction and in proportion to their abilities and capabilities. Setting the goal, i.e. the desire to help the student to define his point of view and enhance his ability to self-learning. (Daloul and Al-Assi, 2008: 143 [7]).

- The discussion and dialogue: (Khawaldeh and Eid) shows that there is a difference between the dialogue and the discussion. Whereas, dialogue is an exchange of ideas and opinions between two parties in a regular and objective manner, while discussion is a discussion of ideas and opinions between two or more parties in depth and investigation. (Al-Khawaldeh and Eid, 2001, 313 [5])

\section{2 - previous studies:}

- Study of (Manal, 2006 [14]): This study was conducted at King Saud University in Saudi Arabia. The aim of the study was to know the effect of using metacognitive thinking strategies through the global information network on academic achievement and the development of higher-order thinking skills among students of the mathematical programming course. The research found the superiority of the experimental group students who used metacognitive thinking strategies through the global information network in academic achievement and the development of higherorder thinking skills over the control group students who did not use them. (Manal, 2006 [14])

- A study of (Stewart and others, 2007): conducted at the University of Houston, USA, and aimed at the effect of using a collaborative team consisting of a virtual course among students, developed by the researchers to increase the educational experience of students in a subject of study on the Internet in order to create a virtual environment for learning. The study reached a number of results that indicate the effectiveness of the virtual environment for learning in developing the educational experience of the students. (Stewart and others 2007 [18])

\section{Research Procedures}

1 - Experimental design: The design of the two equivalent experimental and control groups with (pre-) and (post-) test was chosen to be an appropriate experimental design, as shown in scheme No. (1):

Scheme No. (1): Experimental design of the research 


\begin{tabular}{|l|l|l|l|lr|}
\hline group & $\begin{array}{l}\text { The pre- } \\
\text { application }\end{array}$ & $\begin{array}{l}\text { the independent } \\
\text { variable }\end{array}$ & $\begin{array}{l}\text { the dependent } \\
\text { variable }\end{array}$ & $\begin{array}{l}\text { The post- } \\
\text { application }\end{array}$ \\
\hline Experimental & Creative & Electronic & Creative thinking & creative thinking \\
+ & thinking & collective & +ability to discuss & test & \\
Control & test & contific & & Discussion Ability \\
& & & & & \\
& & & & & \\
& & & & & \\
\hline
\end{tabular}

3.1- Research community: The research community was determined by first-year students in the Department of Electrical Technology at the Technical Institute in Nasiriyah at the Southern Technical University in the Republic of Iraq for the academic year (2017-2018).

\subsection{The research sample:}

It is a random sample of (46) male and female students divided into two groups of equal numbers and equivalent in a number of influential variables, one of them is an experimental group and the other is a control.

\subsection{Research requirements:}

First - Determining the goal of using electronic collective scientific conversations: The two researchers identified the general goal of using electronic collective scientific conversations, which is (the development of creative thinking and the ability to discuss among students of technical universities).

Second - Preparing the necessary plans for the use of electronic collective scientific conversations: The two researchers prepared the necessary plans for students to use electronic collective scientific conversations via the Internet, and what are the procedures that are being taken to achieve the goal of the research. Some specialists were consulted to get their comments and points of views on this subject.

\subsection{Research tools:}

First - Creative Thinking Test: The researchers prepared a creative thinking test. It is a test consisting of a number of items of the multiple choice type and aims to measure the degree of creative thinking among students of technical universities, the research sample, by following the steps recognized in this field, where the goal of it has been determined, which is (measuring the degree of creative thinking among students of technical universities), which is a component in which the instructions were placed to answer it, and it was presented to a number of specialists, based on the (Cooper equation) to calculate the degree of agreement among them, with an agreement rate of (80\%).

A - Extracting the validity of the test: a statistical analysis was achieved to test the creative thinking of students of technical universities by applying it to an exploratory sample other than the research sample consisting of (25) male and female students. The coefficients of discrimination, difficulty and effectiveness of the wrong alternatives were extracted using appropriate statistical methods. It was found that all the items are distinguished and their degree of difficulty is normal, and the wrong alternatives are effective, and thus the scale was considered valid (validity) for the purposes of this research.

B - Extracting the Reliability of the test: The method of re-application was used on the same exploratory sample two weeks after the first application of the test. The reliability coefficient was calculated using Pearson's correlation coefficient $(0.85)$ and the reliability coefficient of the 
Cronbach's alpha equation was (0.88) and the scale became in (Reliability) and valid for application to the research sample in its final form.

First - the form of noting the ability to discuss: The two researchers prepared a form for noting the ability to discuss among the students of technical universities. It consists of a number of items aimed at (measuring the ability to debate among technical university students). It was presented to a number of specialists and based on Cooper's equation to calculate the degree of agreement among them and with an agreement rate of $(80 \%)$.

A - Extracting the validity of the form: the statistical analysis of the form for observing the ability to debate among students of technical universities was carried out by applying it to an exploratory sample other than the research sample (25) male and female students. The coefficients of discrimination and the degree of consistency of the items with the total degree of the form were extracted using the appropriate statistical methods. It was found that all the items are distinct and consistent with each other and with the items of the total form, and thus considered as valid (validity) for the purposes of this research.

B - Extracting the reliability of the form: The method of re-application was used on the same exploratory sample two weeks after the first application. The reliability coefficient was calculated using Pearson's correlation coefficient (0.84) and the reliability coefficient of the Cronbach's alpha equation was (0.86) and the form became in (Reliability) and valid for application to the research sample in its final form.

\section{5 - Steps of applying the research:}

First - Conducting the pre-application of the creative thinking test on the students of the two groups. Second - Analyzing the results of students' answers in the pre-application of the creative thinking test.

Third - Creating a closed group in the WhatsApp application via the Internet between one of the researchers and the students of the experimental group to be a group to conduct electronic collective scientific conversations between them, during which additional information about the subject is exchanged, studied and discussed, which helps them in developing their creative thinking and ability to discuss.

Fourth - The participation of the experimental group students in the electronic collective scientific conversations for a period of five weeks through communication between the researcher and the students and among them.

Fifth - Adopting a form to note the ability to discuss in each lecture and record the results therein.

Sixth - Conducting the post application of the creative thinking test on the students of the two groups.

Seventh - Analyzing the results of students' answers in the post application of the creative thinking test.

Eighth- Comparing the results of the students' answers in the post application of the creative thinking test in each of the two groups and comparing the results of the students' answers on the form of observing the ability to discuss for the two groups.

\section{Research Results}


A - Creative thinking: From the observation of Table (1), we find that: There are statistically significant differences at the moral level (0.05) between the average grades of the experimental group students who used electronic group scientific conversations and the average grades of the control group students who used the usual method in the creative thinking test, in favor of the experimental group.

Table (1): Results of creative thinking

\begin{tabular}{|l|l|l|l|}
\hline Group & Arithmetic mean & Standard deviation & Calculated t value \\
\hline Experimental & 59.91 & 10.433 & 3.476 \\
\hline Control & 70.76 & 9.291 & \\
\hline
\end{tabular}

B - The ability to discuss: From the observation of Table (2), we find that: There are statistically significant differences at the moral level $(0.05)$ between the average grades of the experimental group students who used electronic group scientific conversations and the average grades of the control group students who used the usual method in the form to note the ability to discuss, in favor of the experimental group.

Table (2): Results of the ability of discussion

\begin{tabular}{|l|l|l|l|}
\hline Group & Arithmetic mean & Standard deviation & Calculated t value \\
\hline Experimental & 62.348 & 12.120 & 6.919 \\
\hline Control & 83.045 & 7.833 & \\
\hline
\end{tabular}

C - Discussion of the results: Through the results of the research (in Tables No. 1 and 2), we find that the students of the experimental group who used the electronic collective scientific conversations have benefited from them in developing creative thinking and the ability of discussion to a greater degree than the students of the control group.

This indicates that it is possible to use collective electronic scientific conversations through the Internet. The electronic collective scientific conversations via the Internet were a new method that students were not accustomed to in communicating with others for scientific and cultural topics planned in advance. Thus, they saw in it an interesting method through which they can communicate with others and hold collective scientific conversations, enabling them to talk about it directly and freely and obtain information, topics, instructions, tips and educational guidelines for the purpose of developing creative thinking and the ability of discussion.

\section{Conclusions and Recommendations}

We can summarize the following as the main conclusions:

1 - The use of electronic collective scientific conversations via the Internet has helped in developing creative thinking among students and the ability of discussion among them.

2 - The possibility of developing and enhancing many of the positive aspects of the university student's personality and obtaining a variety of information through various social networking programs via the Internet. 
3 - The possibility of using the Internet in social, scientific, cultural, individual and collective communication among teachers, students and various institutions.

Second - Recommendations:

1 - The use of electronic collective scientific conversations via the Internet in order to develop creative thinking and the ability of discussion among students of technical universities.

2- Interest in conducting applied research to identify the importance of using various social networking programs via the Internet for the purpose of meaningful scientific and cultural exchange between individuals and institutions.

3- Urging the teaching staff in technical universities about the importance of taking advantage of the numerous e-learning applications and using them in order to enhance the positive role of the student in the learning process.

\section{References:}

1. Jarwan Fathi Abdel Rahman (2009). Creativity, its concept, its standards and theories, its measurement and training, and the stages of the creative process, Dar Al-Fikr, Amman, Jordan.

2. Jarwan Abdel-Fattah (2002). Learning to think, concepts and applications, Dar Al-Fikr for printing, publishing and distribution, Amman, Jordan.

3. Jamal, Mohammed Jihad (2005): Developing creative thinking skills through school curricula, 1st Edition, University Book House, Al-Ain, United Arab Emirates.

4. Haris Abdel-Jaber Ammar (2010). The effectiveness of using self-learning based on computer expert systems in teaching in cognitive achievement, developing critical thinking and economic values among first-year secondary students, Faculty of Education, Sohaj University, Egypt (unpublished master's thesis).

5. Khaled Mohammed and Abdel Salam Mohammed (2011). The use of e-learning environments and its relationship to achievement motivation among students of Al-Quds Open University in the northern Gaza educational area. Palestinian Journal of Open Education.

6. Al-Khalili, Amal (2005). Developing children's creativity capabilities, Dar Safaa, Amman, Jordan

7. Dalloul Adnan and Al-Assi Wael (2008). Social subjects and their teaching methods, 2nd edition, Al-Aqsa University. Palestine.

8. Al-Sabti, Wassila (2004). Financing local development within the framework of the South Fund, a study of the reality of development projects in the Wilayat of Biskra, Mohamed Khidher University of Biskra (Unpublished Master's Thesis in Economics)

Al-Surour, Nadia Hael (1996). The effectiveness of the Master-Thinker program for teaching thinking and developing creative skills among a sample of students of the College of Educational Sciences at the University of Jordan, Journal of the Educational Research Center, Qatar University, Issue 10, Volume 5, Qatar

9. Al-Shahrani, Nasser bin Abdullah (2008), The demands of using e-learning in teaching natural sciences in higher education from the specialists point of view, Saudi Arabia, Umm Al-Qura University (unpublished doctoral thesis).

10. Abdel Hadi, Nabil and others (2003). Skills in Language and Thinking, Dar Al Masirah for Publishing and Distribution, Amman, Jordan.

11. Mohammed Mohammed Ali Shaalan (2006): The effectiveness of a program in language activities for the use of classical standerd language to develop some oral expression skills in the preparatory stage, an unpublished master's thesis, Faculty of Education, Ain Shams University. 
12. Mona Hadi Saleh (2013). Studying the possibility of applying a virtual learning environment in educational institutions, Journal of Baghdad College of University Administrative Sciences, special issue, Baghdad College of Administrative Sciences, Baghdad.

13. Manal bint Abdul Rahman Youssef (2006). The effect of using metacognitive thinking strategies through the global information network on academic achievement and developing higher-order thinking skills among female students of the Mathematical Programming Course at King Saud University, College of Education, King Saud University, Saudi Arabia (unpublished master thesis).

14. Nahlawi, Abdul Rahman (2000) Education by Dialogue, House of Contemporary Thought, Beirut, Lebanon.

Wikipedia, the free online encyclopedia

15. Kecmanovic C. Dubravk and Carolyn Weeb. (2000). Toward Communicative Model of Callaborative Web- Mediated Learning, (in) Australian Journal of Education Technology, Vol.16, No.1.

16. Stewarts L. and others (2007). Virtual technology and education collaborative pilot case, The quarterly review of distance education, Vol.7, No.4.

17. Donnelly, A.E (1996). The effect of meta-cognitive skills training on hands - on learning from science objets museums, ERIC no. ED432528. 